\title{
A PRESTAÇÃO DE CONTAS DAS ENTIDADES PRIVADAS SEM FINS LUCRATIVOS EM PARCERIAS COM A UNIÃO (2008 A 2014)
}

\author{
ACCOUNTABILITY OF NON-PROFIT ORGANIZATIONS IN PARTNERSHIPS WITH FEDERAL GOVERNMENT FROM 2008 TO \\ 2014
}

\section{LA RENDICIÓN DE CUENTAS DE LAS ENTIDADES PRIVADAS SIN FINES DE LUCRO EN CONVENIOS CON EL GOBIERNO FEDERAL, 2008 A 2014.}

\section{RESUMO}

A Lei 13.019/2014 reformou o marco regulatório dos convênios e parcerias firmados entre a União e as Entidades Privadas sem Fins Lucrativos (EPSFLs). Este artigo apresenta os conceitos teóricos das EPSFLs e analisa as estatísticas de prestação de contas dos convênios e parcerias dessas entidades com a União, disponíveis no Sistema de Gestão de Convênios e Contratos de Repasse da União (SICONV), de 2008 a 2014. Com base no modelo econométrico, o artigo mostra que a probabilidade de ocorrência de inadimplência é maior para as EPSFLs do que para estados, municípios e empresas públicas, o que reforça a hipótese teórica de falhas voluntárias nas EPSFLs, conforme mostra a Teoria das Três Falhas (Steinberg, 2006).

PALAVRAS-CHAVE: Entidades privadas sem fins lucrativos, accountability, teoria das três falhas, falhas voluntárias, Sistema de Gestão de Convênios e Contratos de Repasse da União.

Sergio Goldbaum ${ }^{1}$

sergio.goldbaum@fgv.br

Euclides Pedrozo $\mathrm{Jr}^{2}$

euclides.pedrozo@fgv.br

Submetido 08.07.2017. Aprovado 08.04.2018

Avaliado pelo processo de double blind review.

DOI: http://dx.doi.org/10.12660/cgpc.v23n74.70160

${ }^{1}$ Fundação Getulio Vargas, Escola de Administração de Empresas de São Paulo, São Paulo, SP, Brasil

2 Universidade Paulista, São Paulo, SP, Brasil 


\begin{abstract}
Law 13,019/2014 reformed the regulatory framework on transfer agreements between the Brazilian Federal Government and non-profit organizations (NPOs). This article presents theoretical concepts on NPOs and analyzes NPOs accountability-related statistics available at the Administrative Agreement and Transfer Contract Management System (Sistema de Gestão de Convênios e Contratos de Repasse da União [SICONV]), for the period from 2008 to 2014. Based on an econometric model, we show that the probability of default for NPOS' agreements is higher than those for states, municipalities and government-owned companies; this corroborates the theoretical hypothesis of NPO voluntary failure as suggested in the Three Failures Paradigm (Steinberg, 2006)
\end{abstract}

Keywords: Non-profit organizations, Accountability, Three Failures Paradigm, Voluntary failures, Sistema de Gestão de Convênios e Contratos de Repasse da União.

\title{
Resumen
}

La ley 13.019/2014 reformó el marco regulatorio de los convenios y contratos de transferencia de recursos, firmados entre el Gobierno Federal y las entidades privadas sin fines de lucro (EPSFL). Este artículo presenta los conceptos teóricos de las EPSFL y analiza las estadísticas de rendición de cuentas de los contratos y convenios de dichas entidades con el Gobierno Federal, disponibles en el Sistema de Gestión de Convenios y Contratos de Transferencia del Gobierno Federal (Sistema de Gestão de Convênios e Contratos de Repasse da União [SICONV]), entre 2008 y 2014. Con base en el modelo econométrico, el artículo muestra que la probabilidad dé incumplimiento es mayor en convenios firmados con las EPSFL que con los estados, municipios y empresas públicas, lo que refuerza la hipótesis teórica de fallos voluntarios en las EPSFL de acuerdo con el modelo de los tres fallos (Steinberg, 2006).

Palabras clave: Entidades privadas sin fines de lucro, rendición de cuentas, modelo de los tres fallos, fallos voluntarios, Sistema de Gestão de Convênios e Contratos de Repasse da União.

\section{INTRODUÇÃO}

Promulgada em 2014, a Lei 13.019 estabeleceu novo marco regulatório para parcerias entre a Administração Pública e as Organizações da Sociedade Civil (OSCs). O ato foi precedido de longo processo de discussão que se iniciou com a formação de Grupo de Trabalho sobre o tema em 2011, no início do primeiro mandato do governo Dilma Rousseff, e se estendeu até às vésperas da promulgação.

Conforme a lei, as Entidades Privadas sem Fins Lucrativos (EPSFLs) representam o conjunto de instituições que tem, de acordo com sua natureza jurídica, o princípio de não auferir lucros. Esse conjunto é composto por organizações da sociedade civil (fundações privadas, organizações religiosas, associações privadas e organizações da sociedade civil de interesse público), entidades ligadas ao serviço social autônomo, entidades sindicais e fundos privados.

As novas normas previstas na Lei 13.019/2014 propuseram regras mais claras para o planejamento dos órgãos públicos na seleção de entidades e na aplicação de recursos durante a execução, o monitoramento e a avaliação do cumprimento do objeto da parceria. A Lei também apresentou melhorias no sistema de prestação de contas das parcerias, diferenciando-as por volume de recursos e provendo os alicerces necessários para que se realize um controle adequado dos resultados.

A evolução da participação das OSCs na oferta de bens e serviços à sociedade por meio de parcerias com o governo federal pode ser conferida em Lopez e Barone (2013), Men- 
donça et al. (2013) e Souto, Pedrozo Jr e Goldbaum (2015). Estes últimos analisaram as informações contidas no Sistema de Gestão de Convênios e Contratos de Repasse da União (SICONV), no qual são registrados todos os atos relativos ao processo de operacionalização das transferências voluntárias de recursos por meio de convênios e outras modalidades, entre 2008 e 2012.

Souto, Pedrozo Jr e Goldbaum (2015) avaliaram diversas ideias comumente difundidas na sociedade que, muitas vezes, não se apoiavam em fundamentos empíricos. A análise confirmou e/ou rejeitou vários desses fatos estilizados, entre eles os que são relacionados à capacidade técnica e organizacional das EPSFLs, que firmaram parcerias com o governo federal ao valor e à finalidade dessas parcerias. Entretanto, um dos temas relevantes da pesquisa - a prestação de contas das EPSFLs - ficou de fora dessa análise, pois os resultados em relação a esse assunto em particular foram, na época, inconclusivos.

O objetivo deste estudo é aprofundar a compreensão das relações entre Estado e EPSFLs, tanto do ponto de vista do escopo de atuação, quanto das obrigações institucionais que esse tipo de relacionamento gera, como, por exemplo, a necessidade de prestação de contas. Para tanto, o tema da prestação de contas das EPSFLs será inserido em arcabouço teórico microeconômico - o "Paradigma das Três Falhas" - conforme apresentado por Steinberg (2006).

A abordagem das Três Falhas baseia-se na insuficiência do mercado e do estado em oferecer bens e serviços a consumidores em decorrência da presença de "falhas de mer- cado" (como a presença de externalidades e assimetrias de informação e, também, a oferta de bens públicos e semipúblicos) e de "falhas de estado" (como a sub-representação política de grupos na sociedade). Mas a teoria também destaca os efeitos das "falhas voluntárias", associadas às organizações sem fins lucrativos, como a insuficiência filantrópica, o particularismo filantrópico, o paternalismo e o amadorismo.

O objetivo específico é analisar os condicionantes da inadimplência nos convênios firmados entre a União e as EPSFLs, comparativamente a outras esferas administrativas (especialmente governos estaduais e municipais), fundamentados nas informações constantes do SICONV, entre 2008 e 2014. A eventual maior incidência de inadimplência nas parceiras firmadas entre a União e EPSFLs reforçaria a hipótese de falhas voluntárias, em especial a do amadorismo: a tendência de contratação de mão de obra menos qualificada por parte de EPSFLs.

O artigo está organizado da seguinte maneira. Após essa introdução, a Seção 2 apresenta revisão conceitual com base na teoria microeconômica sobre as organizações sem fins lucrativos com foco na demanda por serviços prestados por esse tipo de organização. A Seção 3 analisa as estatísticas da prestação de contas das EPSFLs, cujas parcerias com a União estão registradas no SICONV, comparativamente às de outros entes governamentais, em particular dos municípios. A Seção 4 desenvolve exercício econométrico para avaliar a capacidade de EPSFLs em prestar contas nos convênios e parcerias com o governo federal, comparativamente a governos subnacionais e empresas públicas, e também para identificar os 
órgãos convenentes em que a inadimplência é mais frequente. Na última seção são apresentadas as conclusões.

\section{ENTIDADES PRIVADAS SEM FINS LU- CRATIVOS: UMA ABORDAGEM MICROE- CONÔMICA}

Segundo a conhecida definição de Hansmann (1980):

Uma organização sem fins lucrativos é aquela que exclui a distribuição, na forma financeira, dos recursos excedentes (do lucro) para aqueles que estão no controle da organização. (Apud Steinberg, 2006, p. 118).

A "restrição da não distribuição" de lucros

Figura 1. Formas organizacionais reais

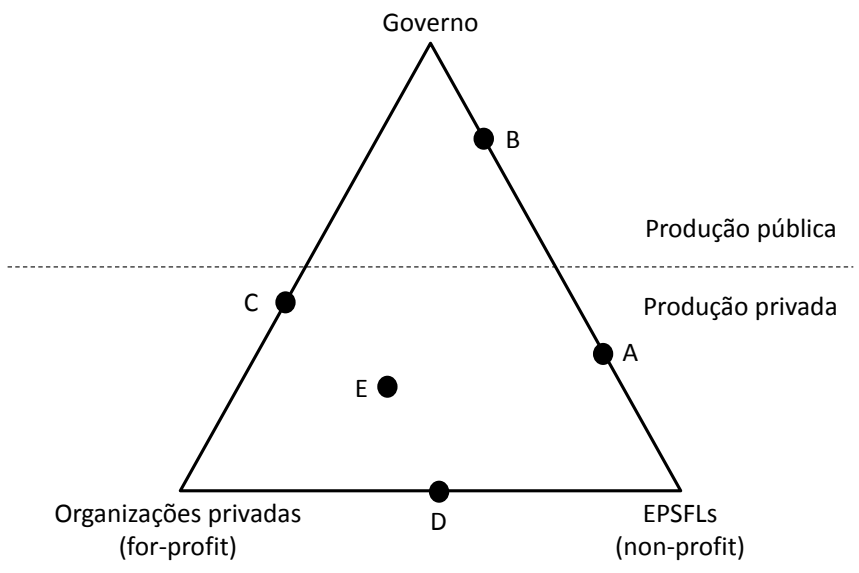

Fonte: Jegers (2008)

O ponto A da Figura 1 representa uma EPSFL integralmente subsidiada pelo Governo. O ponto B, por sua vez, descreve uma organização sem fins lucrativos fundada e subsidiada integralmente pelo governo, como, por exemplo, as fundações mantenedoras de hospitais e universidades públicas. A di- é o ponto central das teorias sobre o comportamento de organizações sem fins lucrativos, afetando "a forma como a organização obtém recursos, como é controlada, como se comporta no mercado, como é percebida pelos doadores e clientes e como seus empregados são motivados.' (Apud Steinberg, 2006, p. 118).

Jegers (2008) critica a definição de Hansmann (1980). Segundo o autor, essa definição leva a três tipos puros (genéricos) de formas organizacionais: governo, setor privado e organizações não governamentais. Nesse contexto, Jeggers (2008) propõe esquema mais abrangente, no qual é possível classificar "formas organizacionais reais", mais complexas, como ilustrado na Figura 1.

ferença entre os dois tipos de organização reside nos instrumentos com que a autoridade governamental conta para forçar a entidade a se comportar de maneira diferente da que se comportaria se não recebesse tais subsídios. No caso das EPSFLs que compõem o ponto $A$, pelo fato de receberem recursos 
públicos, torna-as subordinadas ao órgão convenente, uma vez que ele pode forçar a entidade conveniada a prestar contas sobre a utilização da verba.

No outro lado do triângulo, o ponto $\mathrm{C}$ representa uma organização estatal ou uma empresa com fins lucrativos (for profit) mantida e gerida pelo governo. Na base do triângulo, podemos observar o pondo D que exemplifica instituições como fundações financiadas pelo setor privado ou associações de empresas privadas (comerciais ou industriais). Finalmente, o ponto $\mathrm{E}$, dentro do triângulo, retrata uma EPSFL que pode receber recursos tanto privados quanto governamentais. $O$ fato de ser financiada parcialmente pelo setor público, torna as EPSFLs do ponto $\mathrm{E}$ também subordinadas aos órgãos de con- trole do governo no que se refere à prestação de contas dos recursos tomados.

No que concerne ao escopo da atuação das EPSFLs, pelo lado da demanda, Steinberg (2006) resgatou Weisbrod (1975), Hansmann (1980) e Salamon (1987). Em conjunto, os três autores desenvolveram a conhecida "Teoria das Três Falhas", correspondentes às falhas de mercado, às falhas de governo e às falhas voluntárias. Segundo esse paradigma, o espaço de atuação das EPSFLs é definido pelas insuficiências tanto do mercado quanto do governo para atender a demandas específicas de grupos de consumidores. Esse espaço é também limitado pelas falhas voluntárias, conforme ilustrado na Figura 2 
Figura 2. Esquema da Teoria das Três Falhas

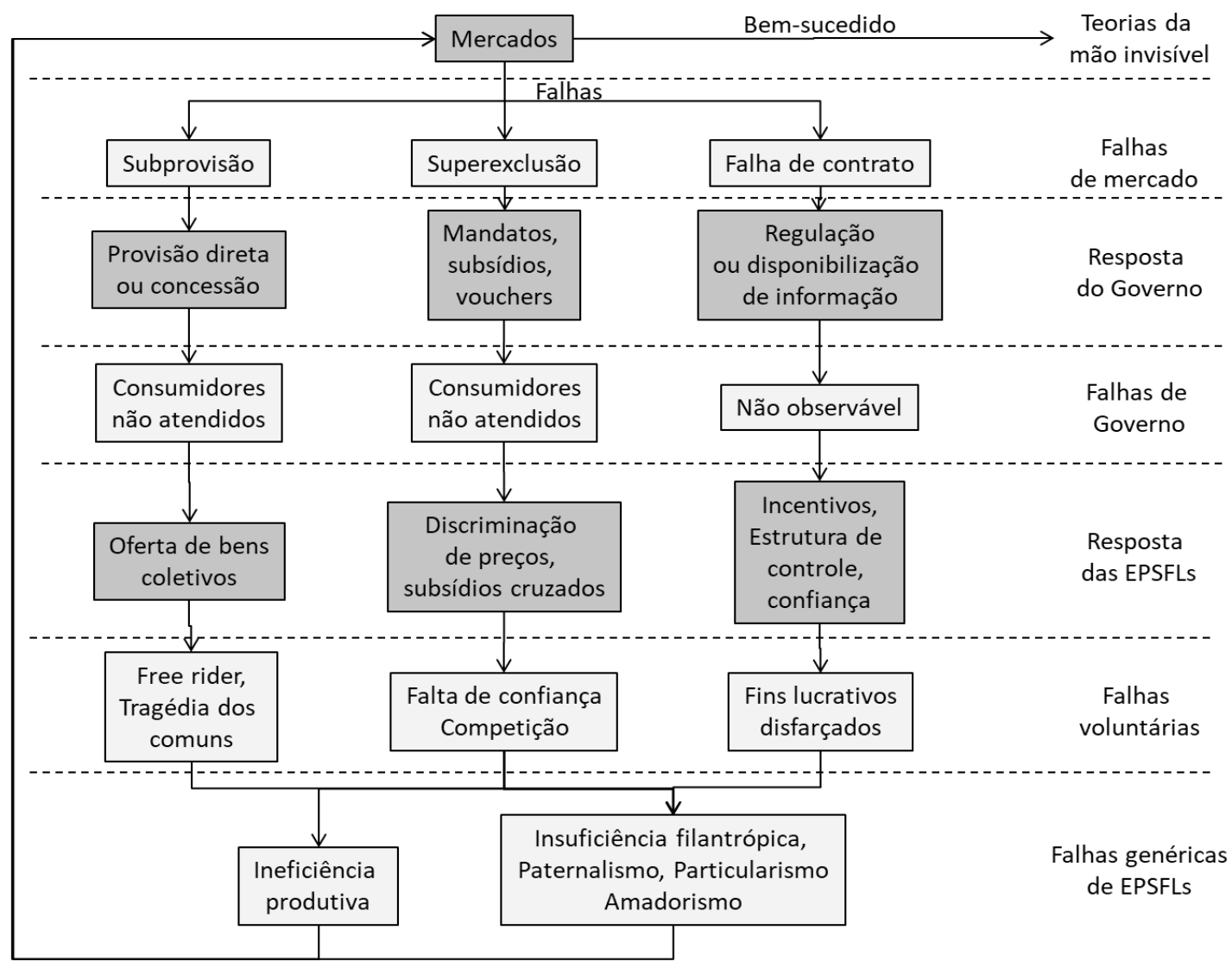

Fonte: Steinberg (2006)

Seguindo a primeira linha da Figura 2, não há necessidade ou espaço para a atuação do estado ou de organizações não governamentais nas situações em que as condições de mercado competitivo prevalecem. Entretanto, a segunda linha da Figura 2 mostra que na presença de falhas de mercado pode ocorrer:

- Subprovisão de bens, como na oferta de bens públicos.

\section{- "Superexclusão" (exclusão excessiva)} de potenciais consumidores, como na oferta de bens semipúblicos (excludentes, mas não rivais); por exemplo, na oferta de educação;
- Falhas de contrato, como nos casos de assimetria de informação e risco moral; por exemplo, na oferta de serviços de assistência social, nos quais a fiscalização da qualidade do serviço prestado é custosa e difícil.

A possível resposta do governo é apresentada na terceira linha:

- Provisão direta ou indireta: no caso da subprovisão de bens públicos, o governo não tem alternativa senão ofertar esse bem ou serviço, ou, ainda, contratar uma empresa privada para ofertar esse bem ou serviço, remunerando-a com recursos públicos.

- Provisão direta ou indireta sujeita à re- 


\section{A PRESTAÇÃo dE CONTAS dAS ENTIDADES PRIVADAS SEM FINS LUCRATIVOS EM PARCERIAS COM A UNIÃo (2008 A 2014)}

gulação: No caso de bens ou serviços semipúblicos, os governos podem oferecer diretamente esses bens ou serviços, estabelecendo os termos da exclusão. Por exemplo, o governo pode exigir requisitos de universalização em monopólios naturais ou ainda oferecer vouchers de educação ou moradia para minorias vulneráveis.

- Regulação de mercados: no caso de assimetria de informações, os governos podem limitar a entrada de agentes no mercado via licenciamento e exigir requisitos de qualidade nos serviços regulados.

Mas a atuação do estado também é limitada pela eventual ocorrência de falhas de governo, como mostra a quarta linha da Figura 2:

- No caso de bens públicos e semipúblicos, haverá consumidores não atendidos em nível local ou específico. A Teoria da EscoIha Pública argumenta que o nível de oferta desses bens será determinado pelas preferências do eleitor mediano, o que significa que até $50 \%$ dos eleitores podem não ter acesso a bens públicos ou semipúblicos desejados

- No caso de falhas de contrato, os governos também estão sujeitos à assimetria de informação e não pode regular abusos que não pode detectar. A fiscalização fica menos custosa para o governo do que para o consumidor, mas isso não significa que não há custos na fiscalização para o estado.

A quinta linha mostra como as EPSFLs suprem os consumidores potenciais não atendidos pelo mercado ou pelo governo. Em particular, as EPSFLs podem:

- Ofertar bens públicos locais ou coletivos a minorias;

- Discriminar preços e praticar subsídios cruzados para aumentar o atendimento de bens semipúblicos;

- Estabelecer incentivos e estruturas de controle baseados na confiança, recurso nem sempre disponível nas relações com o estado ou com as entidades com fins lucrativos.

Finalmente, a atuação das EPSFLs também pode ser limitada pelas falhas voluntárias, apresentadas na sexta e na sétima linha. Comportamentos oportunísticos, ausência de confiança ou de competição e a existência de empresas com fins lucrativos "disfarçadas" de não lucrativos resultam em:

- Insuficiência filantrópica: assim como no caso da oferta pelo mercado ou pelo governo, a oferta de bens coletivos por parte das EPSFLs também pode ser insuficiente por causa da eventual ocorrência de comportamentos oportunísticos do tipo free riders; em particular, doadores podem temer que 0 governo retire suas contribuições de setores atendidos pelas EPSFLs.

- Particularismo filantrópico: tendência de as EPSFLs se concentrarem em etnias, religiões ou grupos ideológicos específicos, levando à duplicação de esforços em alguns casos e à ausência de esforços em outros.

- Paternalismo: tendência de quem trabalha em EPSFLs de tratar os problemas como eles os percebem, e não como eles são para os beneficiários; a ação do governo não estaria sujeita a essa falha na mesma intensidade, uma vez que o governo se submete ao voto periodicamente.

- Amadorismo: tendência a contratar trabaIhadores com menor qualificação profissional.

A seta religando a sétima linha, das falhas de mercado, para a primeira, da iniciativa 
privada, indica que a atuação de cada um dos setores é cíclica, em que cada setor reage às falhas dos outros dois setores, não havendo ordem específica para a atuação de cada setor. Steinberg (2006) também destacou as deficiências da abordagem das três falhas, em particular a ausência de teorias sobre a oferta desse tipo de forma organizacional e o foco exclusivo em eficiência econômica. Eficiência econômica é definida para um conjunto estável de preferências, mas parte importante da atuação dessas EPSFLs objetiva justamente mudanças dessas preferências, o que sugere a importância de uma abordagem multidisciplinar, envolvendo outras ciências sociais aplicadas, como sociologia, antropologia e ciências políticas.

As falhas voluntárias descritas pelo paradigma das Três Falhas, em particular a falha do amadorismo, sugerem maior frequência de inadimplência na prestação de contas por parte das EPSFLs em comparação a organizações privadas e governamentais.

\section{RETRATO E ANÁLISE DA PRESTAÇÃO DE CONTAS POR PARTE DAS EPSFLS QUE FIRMARAM PARCERIAS COM A UNIÃO (2008 A 2014)}

O objetivo desta seção é levantar as informações sobre prestações de contas das parcerias realizadas entre EPSFLs e Governo Federal, durante o período de 2008 a 2014. Das características gerais dessas parcerias, serão analisadas as estatísticas de inadimplência ou ausência de prestação de contas. Os cortes da análise incluem:

a. Tempo de espera após o final da vigência do contrato;

b. Órgão superior convenente; c. Unidade da federação em que a EPSFL é sede;

d. Evolução anual.

O levantamento consistiu, preliminarmente, de coleta de dados junto ao SICONV. O SICONV é o sistema informatizado do governo federal no qual são registrados todos os atos relativos ao processo de operacionalização das transferências voluntárias de recursos por meio de convênios e outras modalidades, desde a sua proposição e análise, passando pela celebração, liberação de recursos e acompanhamento da execução, até a prestação de contas (TCU, 2008, p. 13). Os dados extraídos dessa fonte foram relativos apenas às parcerias celebradas a partir de setembro de 2008, quando foi implantado o referido sistema. As informações foram sistematizadas em base de dados que possibilitou a classificação, quantificação e análise das principais características dos repasses efetuados às Entidades Privadas, incluindo Instituições sem Fins Lucrativos. Além do SICONV, foram utilizadas informações complementares extraídas do Portal da Transparência. A metodologia empregada na estruturação do banco de dados e na sistematização das informações pode ser encontrada em Souto, Pedrozo Jr e Goldbaum (2015).

Características gerais das parcerias celebradas entre EPSFLs e Governo Federal

A Tabela 1 apresenta a relação das parcerias efetivamente celebradas de 2008 a 2014 classificadas por esfera administrativa e por modalidade. Foram contabilizados 79.891 registros de parcerias efetivamente realizadas junto ao governo federal. 


\section{A PRESTAÇ̃̃o de CONTAS dAS ENTIDAdES PRIVAdAS SEM FINS LUCRATIVOS EM PARCERIAS COM A UNIÃo (2008 A 2014)}

Tabela 1. Parcerias efetivamente celebradas, por modalidade e esfera administrativa (20082014)

\begin{tabular}{lrrrr}
\hline Esferas Administrativas & Convênio & Contrato de Repasse & Termo de Parceria & Total de Parcerias \\
Consórcio Público & 78 & 38 & 0 & 116 \\
Empresa Pública/Sociedade Economia & 296 & 160 & 0 & 456 \\
Mista & & & 0 & 7.038 \\
Estadual & 5.286 & 1.752 & 0 & 60.440 \\
Municipal & 14.754 & 45.686 & 120 & 11.841 \\
Privada & 10.780 & 941 & $\mathbf{1 2 0}$ & $\mathbf{7 9 . 8 9 1}$ \\
\hline Total & $\mathbf{3 1 . 1 9 4}$ & $\mathbf{4 8 . 5 7 7}$ & & \\
\hline
\end{tabular}

Fonte: SICONV.

Observa-se que a quantidade de parcerias contratadas com entidades da esfera privada representa cerca de $15 \%$ (ou 11.841 casos) do total, ficando atrás apenas das parcerias efetuadas com entidades da esfera Municipal, que participam com quase $76 \%$. A grande maioria $(91 \%)$ das parcerias do governo federal com EPSFLs é instrumentalizada na forma de convênios. As parcerias com entidades estaduais e com outros entes classificados no SICONV (Empresa Pública/Sociedade de Economia Mista e Consórcio Público) não chegam a 10\% do total de parcerias efetivamente celebradas.

As características gerais das parcerias firmadas entre 2008 e 2014 constam na Tabela
2. Do total de 11.841 parcerias com EPSFLs registradas no SICONV na data-base, $29 \%$ (ou 1.633 parcerias) estavam em execução e as $71 \%$ restantes finalizadas. Do total de parcerias efetivamente contratadas, $41 \%$ apresentavam termos de aditivos e, mais da metade das parcerias (53\% do total), prorrogações de ofício. A data-base da extração dos dados foi 14/01/2015. Em razão do caráter dinâmico das parcerias registradas no SICONV, dados extraídos em outras datas podem apresentar resultados diferentes dos deste estudo. Dessa forma, optou-se por uma análise estática das parcerias celebradas de 2008 a 2014, considerando a data-base de extração dos dados. Ver Souto, Pedrozo Jr e Goldbaum (2015)

Tabela 2. Características gerais: evolução total das parcerias com EPSFLs (2008-2014)

\begin{tabular}{lrrrrrrrr}
\hline Características & $\mathbf{2 0 0 8}$ & $\mathbf{2 0 0 9}$ & $\mathbf{2 0 1 0}$ & $\mathbf{2 0 1 1}$ & $\mathbf{2 0 1 2}$ & $\mathbf{2 0 1 3}$ & $\mathbf{2 0 1 4}$ & Total \\
Total & $\mathbf{8 1 1}$ & $\mathbf{2 . 5 3 2}$ & $\mathbf{2 . 9 9 5}$ & $\mathbf{1 . 4 5 2}$ & $\mathbf{1 . 2 5 9}$ & $\mathbf{1 . 1 5 9}$ & $\mathbf{1 . 6 3 3}$ & $\mathbf{1 1 . 8 4 1}$ \\
Em execução & $0 \%$ & $\mathbf{7} \%$ & $11 \%$ & $22 \%$ & $35 \%$ & $59 \%$ & $93 \%$ & $29 \%$ \\
Finalizados & $100 \%$ & $93 \%$ & $89 \%$ & $78 \%$ & $65 \%$ & $41 \%$ & $7 \%$ & $71 \%$ \\
Aditivados & $34 \%$ & $43 \%$ & $46 \%$ & $66 \%$ & $63 \%$ & $30 \%$ & $4 \%$ & $41 \%$ \\
Prorrogar de ofício & $45 \%$ & $57 \%$ & $68 \%$ & $67 \%$ & $66 \%$ & $47 \%$ & $2 \%$ & $53 \%$ \\
\hline
\end{tabular}

Fonte: SICONV. 
A Tabela 2 permite também observar a evolução anual das características gerais das parcerias. Por exemplo, nenhum contrato celebrado em 2008 estava em execução na data base da extração dos dados. Em relação às parcerias firmadas em 2009, 93\% estavam finalizadas. Nas parcerias de 2014, a proporção se inverte: somente $7 \%$ delas estavam finalizadas na data-base. No total de parcerias efetuadas entre 2011 e 2014, cerca de $29 \%$ estão em execução.

A Tabela 3 apresenta a quantidade de parce- rias celebradas pelos órgãos convenentes, entre 2008 e 2014, representados pela Presidência da República (Administração Direta) e por 27 Ministérios (incluindo seis secretarias especiais da Presidência da República com status de Ministério). Observa-se que a maioria de parcerias foi celebrada junto ao Ministério da Saúde (precisamente: 43,8\%). Todos os demais órgãos convenentes apresentaram participação inferior a 10\%. Entre eles, podem ser destacados o Ministério da Cultura e o do Turismo (com 9,7\% e 8,6\%, respectivamente).

Tabela 3. Órgão superior convenente: evolução das parcerias com EPSFLS (2008-2014)

\begin{tabular}{|c|c|c|c|c|c|c|c|c|}
\hline $\begin{array}{l}\text { Órgão superior } \\
\text { Convenente }\end{array}$ & 2008 & 2009 & 2010 & 2011 & 2012 & 2013 & 2014 & Total \\
\hline Ministério da Saúde & 0 & 617 & 1.061 & 953 & 693 & 561 & 1.298 & 5.183 \\
\hline Ministério da Cultura & 146 & 408 & 440 & 27 & 39 & 59 & 31 & 1.150 \\
\hline Ministério do Turismo & 170 & 469 & 370 & 11 & 1 & 2 & 0 & 1.023 \\
\hline Ministério da Educação & 7 & 26 & 97 & 116 & 183 & 271 & 186 & 886 \\
\hline Ministério do Desenvolvimento Agrário & 89 & 213 & 196 & 15 & 46 & 35 & 29 & 623 \\
\hline Ministério do Esporte & 77 & 138 & 179 & 49 & 64 & 11 & 8 & 526 \\
\hline Ministério da Agricultura, Pecuária e Abastecimento & 40 & 114 & 110 & 52 & 23 & 28 & 17 & 384 \\
\hline Ministério do Trabalho e Emprego & 88 & 109 & 87 & 11 & 30 & 30 & 8 & 363 \\
\hline Secretaria de Direitos Humanos & 58 & 77 & 74 & 51 & 33 & 54 & 8 & 355 \\
\hline Demais & 136 & 361 & 381 & 167 & 147 & 108 & 48 & 1348 \\
\hline Total & 811 & 2.532 & 2.995 & 1.452 & 1.259 & 1.159 & 1.633 & 11.841 \\
\hline
\end{tabular}

Fonte: SICONV.

A Tabela 4 classifica as parcerias celebradas com EPSFLs, entre 2008 e 2014, por faixas de valor de repasse nominal. $O$ valor de repasse de uma parceria é igual ao valor global do contrato subtraído da contrapartida (financeira ou em bens e serviços) que a conveniada eventualmente tenha efetuado. Optou-se por utilizar os valores nominais, sem atualização monetária, pois a data de contratação não significa exatamente a do repasse, que pode ser efetuado, ainda, em diversas parcelas de acordo com os planos de aplicação e empenhos, dificultando a definição da data-base de atualização monetária.

Ao analisar o período todo, observa-se que as parcerias estão relativamente bem distribuídas pelas faixas definidas na Tabela 4.0 valor de repasse da maior parte das parcerias firmadas no período (29\%) está entre $R \$$ 200 mil e $R \$ 600$ mil. Entre $R \$ 100$ mil e $R \$$ 200 mil e até $R \$ 100$ mil, a participação é a mesma: $25 \%$. As parcerias de maior valor, de 
A PRESTAÇÃO DE CONTAS DAS ENTIDADES PRIVADAS SEM FINS LUCRATIVOS EM PARCERIAS COM A UNIÃO (2008 A 2014)

$\mathrm{R} \$ 600$ mil a $\mathrm{R} \$ 1$ milhão e acima de $\mathrm{R} \$ 1$ de parcerias firmadas, respectivamente. milhão, respondem por $8 \%$ e $13 \%$ do total

Tabela 4. Faixa de valores de repasse dos contratos com EPSFLs: evolução das parcerias por modalidade (2008-2014)

\begin{tabular}{lrrrrrrrr}
\hline Faixa de Valor de & $\mathbf{2 0 0 8}$ & $\mathbf{2 0 0 9}$ & $\mathbf{2 0 1 0}$ & $\mathbf{2 0 1 1}$ & $\mathbf{2 0 1 2}$ & $\mathbf{2 0 1 3}$ & $\mathbf{2 0 1 4}$ & Total \\
Repasse & $\mathbf{1 7 6}$ & $\mathbf{2}$ & $\mathbf{9 6 5}$ & 346 & 226 & 171 & 286 & 2.994 \\
Até 100 mil & 215 & 595 & 801 & 373 & 251 & 260 & 487 & 2.982 \\
de 100 mil a 200 mil & 229 & 676 & 741 & 393 & 407 & 403 & 593 & 3.442 \\
de 200 mil a 600 mil & 53 & 165 & 182 & 121 & 126 & 96 & 148 & 891 \\
de 600 mil a 1 milhão & 138 & 272 & 306 & 219 & 249 & 229 & 119 & 1.532 \\
acima de 1 milhão & $\mathbf{8 1 1}$ & $\mathbf{2 . 5 3 2}$ & $\mathbf{2 . 9 9 5}$ & $\mathbf{1 . 4 5 2}$ & $\mathbf{1 . 2 5 9}$ & $\mathbf{1 . 1 5 9}$ & $\mathbf{1 . 6 3 3}$ & $\mathbf{1 1 . 8 4 1}$ \\
\hline Total & & & & & & &
\end{tabular}

Fonte: SICONV.

Características das parcerias finalizadas

As parcerias da União finalizadas são aquelas que já tiveram sua data de vigência encerrada antes da data de extração de dados. As parcerias finalizadas são subdivididas entre aquelas que estão "aguardando prestação de contas" ou estão "inadimplentes" e aquelas que já entregaram a prestação de contas. As análises dessa subseção se concentram exatamente nas parcerias que não entregaram a prestação de contas na data-base.

No SICONV, não é clara a distinção entre as situações "aguardando prestação de contas" e "inadimplente." Para efeitos da análise dessa subseção, as duas situações devem ser entendidas como única, ou seja, que o convenente não entregou a prestação de contas após o encerramento do contrato. Mais adiante, serão classificadas como inadimplentes somente aquelas que não entregaram a prestação de contas por mais de 90 dias após o fim da vigência.

A Tabela 5 apresenta a situação das parce- rias contratadas junto ao Governo Federal, subdivididas por esfera administrativa. Em sua totalidade, a proporção de parcerias finalizadas (38.715, ou $48 \%$ ) é ligeiramente inferior à de parcerias ainda em execução (41.176, ou $52 \%$ ). Considerando apenas as EPSFLs, a quantidade de convênios finalizados é bem superior aos que ainda estão em execução: 7.434 parcerias finalizadas (63\% do total de parcerias com EPSFLs) contra 4.407 em execução (37\%).

A Tabela 5 também permite observar a situação das parcerias finalizadas que ainda estão "aguardando prestação de contas" ou estão registradas como "inadimplentes" no SICONV. Para as EPSFLs, nota-se que $21 \%$ das parcerias finalizadas não entregaram a prestação de contas, enquanto para as outras esferas, o total de parcerias finalizadas que estão nessa situação é inferior (14\%). Por outro lado, dos $79 \%$ de parcerias com EPSFLs finalizadas, observa-se uma distribuição equilibrada entre as situações "Prestação de Contas Aprovadas" (23\%), Prestação de Contas Enviada para Análise" (20\%), "Prestação de Contas Aprovadas com Res- 
salvas" (14\%) e "Prestação de Contas em Análise" (13\%). Já entre os $86 \%$ de contratos finalizados das outras esferas, a maioria está em situação "Prestação de Contas Aprovada" $(62 \%)$.

Tabela 5: Situação das parcerias por esfera administrativa (2008-2014)

\begin{tabular}{|c|c|c|c|c|c|c|c|}
\hline Situação da parceria & $\begin{array}{l}\text { Consórcio } \\
\text { público }\end{array}$ & $\begin{array}{l}\text { Empr. Públical } \\
\text { Soc. Econ. Mista }\end{array}$ & Estadual & Municipal & $\begin{array}{r}\text { Total: Outros } \\
\text { Entes }\end{array}$ & EPSFLs & Total \\
\hline Em execução & 81 & 244 & 4.146 & 32.298 & 36.769 & 4.407 & 41.176 \\
\hline Finalizados: & 35 & 212 & 2.892 & 28.142 & 31.281 & 7.434 & 38.715 \\
\hline Inadimplente & 0 & 2 & 6 & 186 & 194 & 422 & 616 \\
\hline Aguardando prestação de contas & 6 & 26 & 523 & 3.479 & 4.034 & 1.102 & 5.136 \\
\hline Prestação de contas enviada para análise & 7 & 41 & 873 & 2.806 & 3.727 & 1.503 & 5.230 \\
\hline Prestação de contas em análise & 6 & 32 & 418 & 1.651 & 2.107 & 967 & 3.074 \\
\hline Prestação de contas em complementação & 1 & 17 & 180 & 758 & 956 & 603 & 1.559 \\
\hline Prestação de contas aprovada & 15 & 85 & 754 & 18.606 & 19.460 & 1.715 & 21.175 \\
\hline $\begin{array}{l}\text { Prestação de contas aprovada com res- } \\
\text { salva }\end{array}$ & 0 & 8 & 120 & 536 & 664 & 1.050 & 1.714 \\
\hline Prestação de contas rejeitada & 0 & 1 & 16 & 112 & 129 & 60 & 189 \\
\hline $\begin{array}{l}\text { Prestação de contas iniciada por anteci- } \\
\text { pação }\end{array}$ & 0 & 0 & 2 & 8 & 10 & 12 & 22 \\
\hline Total & 116 & 456 & 7.038 & 60.440 & 68.050 & 11.841 & 79.891 \\
\hline
\end{tabular}

Fonte: SICONV.

A Tabela 6 apresenta a evolução das parcerias efetuadas com EPSFLs entre 2008 e 2014 quanto à situação de cada uma. As parcerias que estão "aguardando prestação de contas" ou "inadimplentes" nessa tabela são classificadas, agora, como aquelas que estão dentro do prazo de 90 dias após a vigência, incluindo também as que não enviaram a prestação de contas após esse prazo. Desse modo, é possível distinguir as parcerias finalizadas que estão no prazo legal de entrega da prestação de contas física e financeira daquelas que estão efetivamente inadimplentes. Na regra vigente na data-base de extração dos dados, as EPSFLs tinham 60 dias para submeter a prestação de contas ao sistema. Após esse prazo, o atraso já era registrado no Sistema Integrado de Administração Financeira do Governo Federal (SIAFI), com a instauração de Tomada de Contas Especial, incluindo um compromisso de entrega em 30 dias. Desse modo, das 1.524 parcerias finalizadas que estão registradas como "aguardando prestação de contas" ou "inadimplentes", 135 ainda estão dentro do prazo legal de 90 dias para apresentar a prestação de contas. Sendo assim, restam 1.389 parcerias (ou 19\% do total de parcerias finalizadas) que estão efetivamente inadimplentes por não terem prestado contas além dos 90 dias após o fim da vigência do contrato.

A maioria das parcerias inadimplentes é rela- 


\section{A PRESTAÇ̃̃o dE CONTAS dAS ENTIDADES PRIVADAS SEM FINS LUCRATIVOS EM PARCERIAS COM A UNIÃo (2008 A 2014)}

tiva a contratos efetivados em 2009 e 2010. Nesses anos, $25 \%$ e $20 \%$, respectivamente, das parcerias finalizadas não apresentaram prestação de contas. Destaca-se também que, do total das parcerias firmadas em 2008 e já finalizadas, $26 \%$ estão inadimplentes. Nos anos seguintes, sempre na comparação com as parcerias finalizadas, a proporção de inadimplência caiu: a proporção de parcerias sem prestação de contas nos anos de 2011 e 2012 é 7\% cada; nas parcerias assinadas em 2013, o percentual é ainda menor (2\%) e se verifica um ligeiro crescimento na inadimplência em 2014 (3\%).

Tabela 6. Situação das parcerias efetuadas com EPSFLs: evolução total (2008-2014)

\begin{tabular}{|c|c|c|c|c|c|c|c|c|}
\hline Situação da parceria & 2008 & 2009 & 2010 & 2011 & 2012 & 2013 & 2014 & Total \\
\hline Em execução & 4 & 231 & 448 & 490 & 640 & 993 & 1.601 & 4.407 \\
\hline Finalizados: & 807 & 2.301 & 2.547 & 962 & 619 & 166 & 32 & 7.434 \\
\hline Aguardando prestação de contas ou inadimplentes & 210 & 591 & 535 & 95 & 68 & 23 & 2 & 1.524 \\
\hline Dentro do prazo de 90 dias após o fim da vigência & 0 & 26 & 33 & 29 & 26 & 20 & 1 & 135 \\
\hline Por mais de 90 dias após o fim da vigência & 210 & 565 & 502 & 66 & 42 & 3 & 1 & 1.389 \\
\hline Prestação de contas enviada: & 597 & 1.710 & 2.012 & 867 & 551 & 143 & 30 & 5.910 \\
\hline Prestação de contas enviada para análise & 142 & 355 & 472 & 228 & 237 & 59 & 10 & 1.503 \\
\hline Prestação de contas em análise & 190 & 354 & 245 & 99 & 44 & 30 & 5 & 967 \\
\hline Prestação de contas em complementação & 74 & 167 & 246 & 69 & 37 & 6 & 4 & 603 \\
\hline Prestação de contas aprovada & 167 & 518 & 631 & 243 & 108 & 37 & 11 & 1.715 \\
\hline Prestação de contas aprovada com ressalva & 21 & 296 & 384 & 222 & 120 & 7 & 0 & 1.050 \\
\hline Prestação de contas rejeitada & 3 & 19 & 32 & 5 & 1 & 0 & 0 & 60 \\
\hline Prestação de contas iniciada por antecipação & 0 & 1 & 2 & 1 & 4 & 4 & 0 & 12 \\
\hline Total & 811 & 2.532 & 2.995 & 1.452 & 1.259 & 1.159 & 1.633 & 11.841 \\
\hline
\end{tabular}

Fonte: SICONV.

Dos registros do SICONV, é possível identificar a subsituação das parcerias. Essa variável mostra se determinada parceria está passando por fase de ajustes pelo convenente ou não. Desse modo, uma parceria pode apresentar como justificativa para o atraso na entrega da prestação de contas o fato de estar "em aditivação", "em ajuste do plano de trabalho", "em ajuste pelo concedente", "em ajuste pelo convenente", "em complementação prorroga" e "em prorrogação". Quando a subsituação da parceria não apresenta registro dessas características, ela é identificada como "Convênio", significando dizer que não há motivos de ajuste para o atraso na entrega da prestação de contas. A Tabela 7 apresenta o resumo do cruzamento das parcerias finalizadas com atraso na entrega da prestação de contas com a variável de subsituação. 
Tabela 7. Caracterização das parcerias com EPSFLs finalizadas e com atraso na entrega da prestação de contas (2008-2014)

\begin{tabular}{|c|c|c|c|c|c|c|c|c|c|c|}
\hline $\begin{array}{l}\text { Faixa de tempo após o } \\
\text { fim da vigência }\end{array}$ & Convênio & $\begin{array}{l}\text { Em Aditiva- } \\
\text { ção }\end{array}$ & $\begin{array}{l}\text { Em } \\
\text { ajuste do } \\
\text { plano } \\
\text { de traba- } \\
\text { lho }\end{array}$ & $\begin{array}{l}\text { Em } \\
\text { ajuste pelo } \\
\text { convenente }\end{array}$ & $\begin{array}{l}\text { Em } \\
\text { Ajuste pelo } \\
\text { Convenente }\end{array}$ & & $\begin{array}{l}\text { Em Comple- } \\
\text {-mentação/ } \\
\text { prorroga }\end{array}$ & & $\begin{array}{l}\text { Em } \\
\text { Prorroga- } \\
\text {-ção }\end{array}$ & Total \\
\hline Até 90 dias & 126 & 5 & 2 & 0 & & 2 & & 0 & 0 & 135 \\
\hline Mais de 90 dias & 1.259 & 27 & 27 & 2 & & 11 & & 7 & 56 & 1.389 \\
\hline Entre 3 e 6 meses & 54 & 1 & 1 & 0 & & 1 & & 0 & 0 & 57 \\
\hline Entre 6 meses e 1 ano & 69 & 1 & 4 & 0 & & 1 & & 0 & 0 & 75 \\
\hline Entre 1 ano e 2 anos & 138 & 3 & 5 & 1 & & 1 & & 3 & 0 & 151 \\
\hline Acima de 2 anos & 998 & 22 & 17 & 1 & & 8 & & 4 & 56 & 1.106 \\
\hline Total & 1.385 & 32 & 29 & 2 & & 13 & & 7 & 56 & 1.524 \\
\hline
\end{tabular}

Fonte: SICONV.

As primeiras duas linhas da Tabela 7 reproduzem o resultado das parcerias finalizadas que estão aguardando prestação de contas/ inadimplentes constantes na Tabela 6. As 135 parcerias com atraso até 90 dias estão dentro do prazo previsto em Lei. Observa-se, entretanto, que das 1.389 parcerias com prestação de contas atrasadas por mais de 90 dias, 130 estão caracterizadas com alguma subsituação de ajustes que justificaria o atraso. As outras 1.259 parcerias (ou 16,9\% das parcerias finalizadas) são aquelas que estão inadimplentes e sem nenhuma justificativa de acordo com o SICONV. A Figura 3 sintetiza a situação de todas as parcerias finalizadas efetuadas com EPSFLs ao longo do período analisado, bem como uma comparação com a situação daquelas efetuadas com outras esferas administrativas. 
Figura 3. Situação das parcerias com EPSFLs finalizadas e sua comparação com outras esferas administrativas (2008-2014)

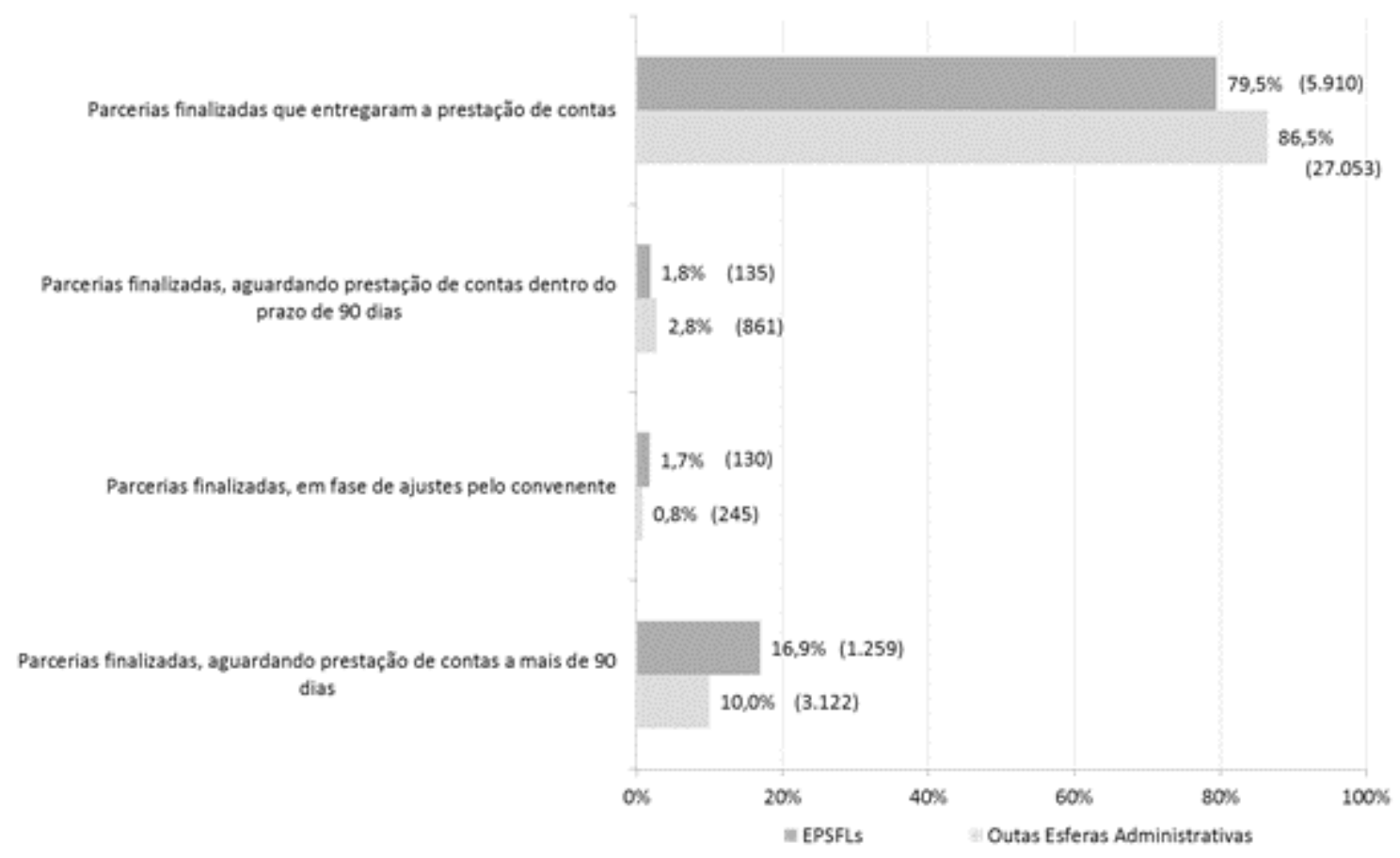

Fonte: SICONV.

Conforme ilustrado na Figura 3, a proporção de parcerias em atraso com a prestação de contas por mais de 90 dias sem justificativa de ajustes é maior entre as EPSFLs (16,9\% contra apenas $10 \%$ das outras esferas administrativas e empresas públicas).

Retornando à Tabela 7, observa-se que, do conjunto de parcerias inadimplentes e sem justificativa, a maioria está atrasada a mais de 2 anos com a entrega da prestação de contas (998 parcerias ou 79\%). Nos outros casos, entre 1 ano e 2 anos de atraso são verificadas - 138 parcerias (11\%) -, 69 parcerias estão atrasadas entre 6 meses e 1 ano (5\%) e apenas 54 parcerias estão atrasadas a menos de 6 meses. A Figura 4 apresenta a comparação desses resultados com os verificados em parcerias com outras esferas administrativas. Observa-se também maior proporção de parcerias inadimplentes, há mais de 2 anos, tanto nas EPSFLs quanto nas de outras esferas. No entanto, a participação de atraso superior a dois anos é maior nas parcerias com EPSFLs $(79,3 \%$ contra $54,7 \%$ dos outros entes). 
Sergio Goldbaum - Euclides Pedrozo Jr

Figura 4. Tempo de atraso da prestação de contas de parcerias finalizadas (2008-2014)

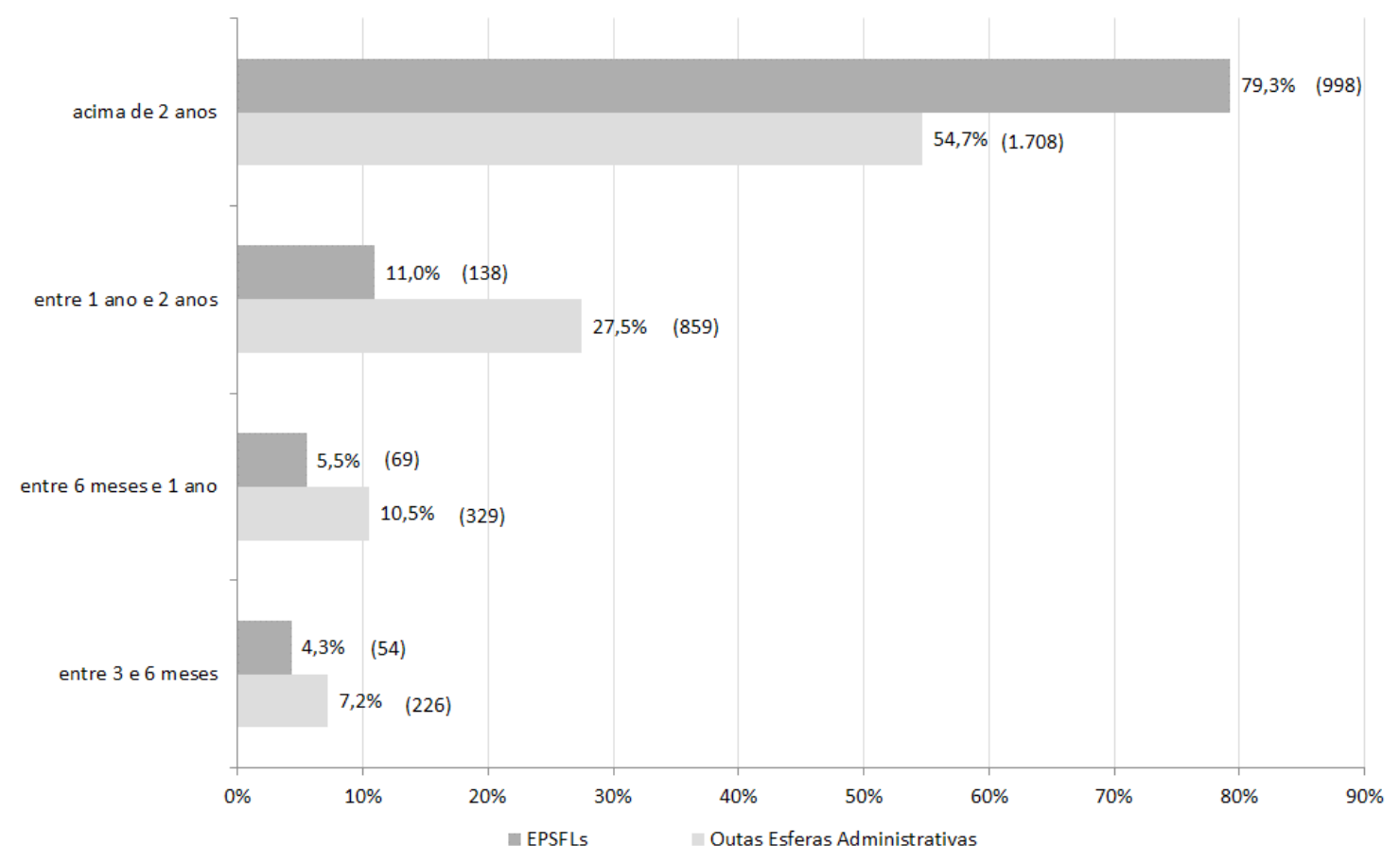

Fonte: SICONV.

A Figura 5 exibe a comparação de parcerias inadimplentes de EPSFLs e de outras esferas administrativas quanto ao tempo de vigência dos contratos. Percebe-se que a maioria das parcerias com EPSFLs que não apresentaram a prestação de contas tem prazo de vigência curto (até 6 meses). Considerando os contratos com vigência inferior a 2 anos, as parcerias com EPSFLS inadimplentes chega a $78 \%$. Apenas $22 \%$ das parcerias inadimplentes tem prazo acima de 2 anos. No caso das outras esferas administrativas é clara a relação contrária: por um lado, a maioria das parcerias com EPSFLs que não apresentaram a prestação de contas tem prazo de vigência médio (entre 1 ano e 2 anos); por outro lado, considerando a totalidade dos contratos com vigência superior a 2 anos, as parcerias inadimplentes de outras esferas alcança $86 \%$. Dessa forma, somente $14 \%$ das parcerias inadimplentes de outros entes tem prazo inferior a 1 ano. Em suma, o perfil das parcerias com EPSFLs que estão inadimplentes apresenta prazo curto; já o perfil do atraso na entrega de prestação de contas por parte das outras esferas tem longo prazo. 
Figura 5. Parcerias finalizadas inadimplentes por faixa de tempo de vigência dos contratos (2008-2014)

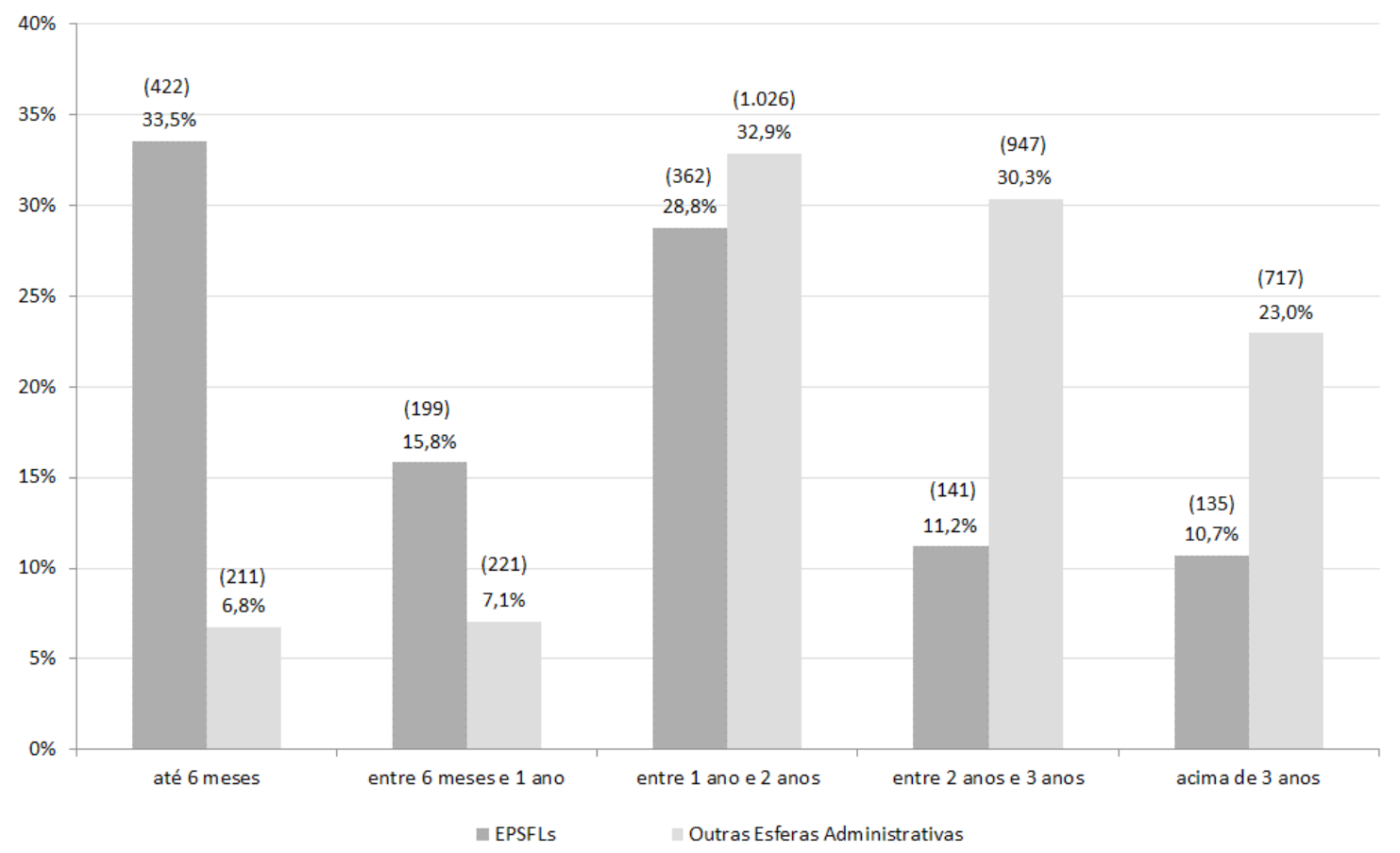

Fonte: SICONV.

A Tabela 8 retrata a avaliação dos valores envolvidos nas parcerias efetuadas com o governo federal. De um modo geral, o valor médio das parcerias com EPSFLs finalizadas é quase o dobro da verificada em outras esferas administrativas $(R \$ 805,6$ mil contra $R \$ 448,6$ mil). Esse resultado se repete quando se avalia apenas as parcerias adimplentes ( $\mathrm{R} \$ 845,8$ mil para as EPSFLs e $R \$ 437,8$ mil para as parcerias com outros entes). Também em relação às parcerias inadimplentes, os maiores valores envol- vidos pendem para o lado das EPSFLs. $O$ total repassado paras as EPSFLs que não apresentaram prestação de contas chega a $R \$ 766$ milhões (13\% do total repassados a todas as EPSFLs). A participação do valor envolvido em atrasos de outros entes no total dos repasses é similar: $12 \%$. O valor de repasse médio das parcerias com EPSFLS inadimplentes atinge $\mathrm{R} \$ 608,2$ mil. Para as parcerias com atrasos na prestação de contas de outros entes o valor médio é $R \$ 546,2$ mil. 
Sergio Goldbaum - Euclides Pedrozo Jr

Tabela 8. Parcerias com governo federal finalizadas: valores empenhados, 2008-2014

\begin{tabular}{|c|c|c|c|c|c|c|}
\hline \multirow[b]{2}{*}{$\begin{array}{l}\text { Situação da entidade em relação } \\
\text { à prestação de contas }\end{array}$} & \multicolumn{3}{|c|}{ Parcerias finalizadas com EPSFLs } & \multicolumn{3}{|c|}{$\begin{array}{l}\text { Parcerias finalizadas com outras } \\
\text { esferas administrativas }\end{array}$} \\
\hline & $\begin{array}{r}\text { N. de } \\
\text { parcerias }\end{array}$ & $\begin{array}{r}\text { Valor de re- } \\
\text { passe } \\
(R \$ 1.000)\end{array}$ & $\begin{array}{l}\text { Valor de re- } \\
\text { passe médio } \\
\text { por parceira } \\
\text { (R\$ 1.000) }\end{array}$ & $\begin{array}{r}\text { N. de } \\
\text { parcerias }\end{array}$ & $\begin{array}{r}\text { Valor de re- } \\
\text { passe } \\
(R \$ 1.000)\end{array}$ & $\begin{array}{r}\text { Valor de repasse } \\
\text { médio por parceira } \\
(\mathrm{R} \$ 1.000)\end{array}$ \\
\hline Adimplentes & 6.175 & $5.223 .077,8$ & 845,8 & 28.159 & $12.328 .510,4$ & 437,8 \\
\hline Inadimplentes & 1.259 & $765.683,8$ & 608,2 & 3.122 & $1.705 .139,7$ & 546,2 \\
\hline Entre 3 e 6 meses & 54 & $39.191,2$ & 725,8 & 226 & $111.780,7$ & 494,6 \\
\hline Entre 6 meses e 1 ano & 69 & $42.924,3$ & 622,1 & 329 & $157.607,6$ & 479,1 \\
\hline Entre 1 ano e 2 anos & 138 & $102.648,7$ & 743,8 & 859 & $458.098,2$ & 533,3 \\
\hline Acima de 2 anos & 998 & $580.919,6$ & 582,1 & 1.708 & $977.653,2$ & 572,4 \\
\hline Total & 7.434 & $5.988 .761,7$ & 805,6 & 31.281 & $14.033 .650,1$ & 448,6 \\
\hline
\end{tabular}

Fonte: SICONV.

A Figura 6 compara parcerias inadimplentes de EPSFLs com a de outras esferas administrativas quanto à faixa de valor de repasse dos contratos. É clara a observação de que as faixas de valores que mais incidem em inadimplência, independentemente da esfera administrativa, são as que estão entre $\mathrm{R} \$ 100$ mil e $\mathrm{R} \$ 600$ mil. Mas, destaca-se que, na faixa de valores abaixo de $R \$ 100$ mil, as parcerias inadimplentes das EPS-
FLs são bem maiores do que as verificadas em outros entes, tanto em valores absolutos (quase três vezes maior) quanto relativos (14 pontos percentuais mais alto). Além disso, também é superior à proporção de parcerias com EPSFLs atrasadas na prestação de contas de contratos com valores de repasse mais altos, acima de $R \$ 1$ milhão (14,1\% contra $9,8 \%$ de outras esferas). 
Figura 6. Parcerias finalizadas inadimplentes por faixa de valor de repasse (2008-2014)

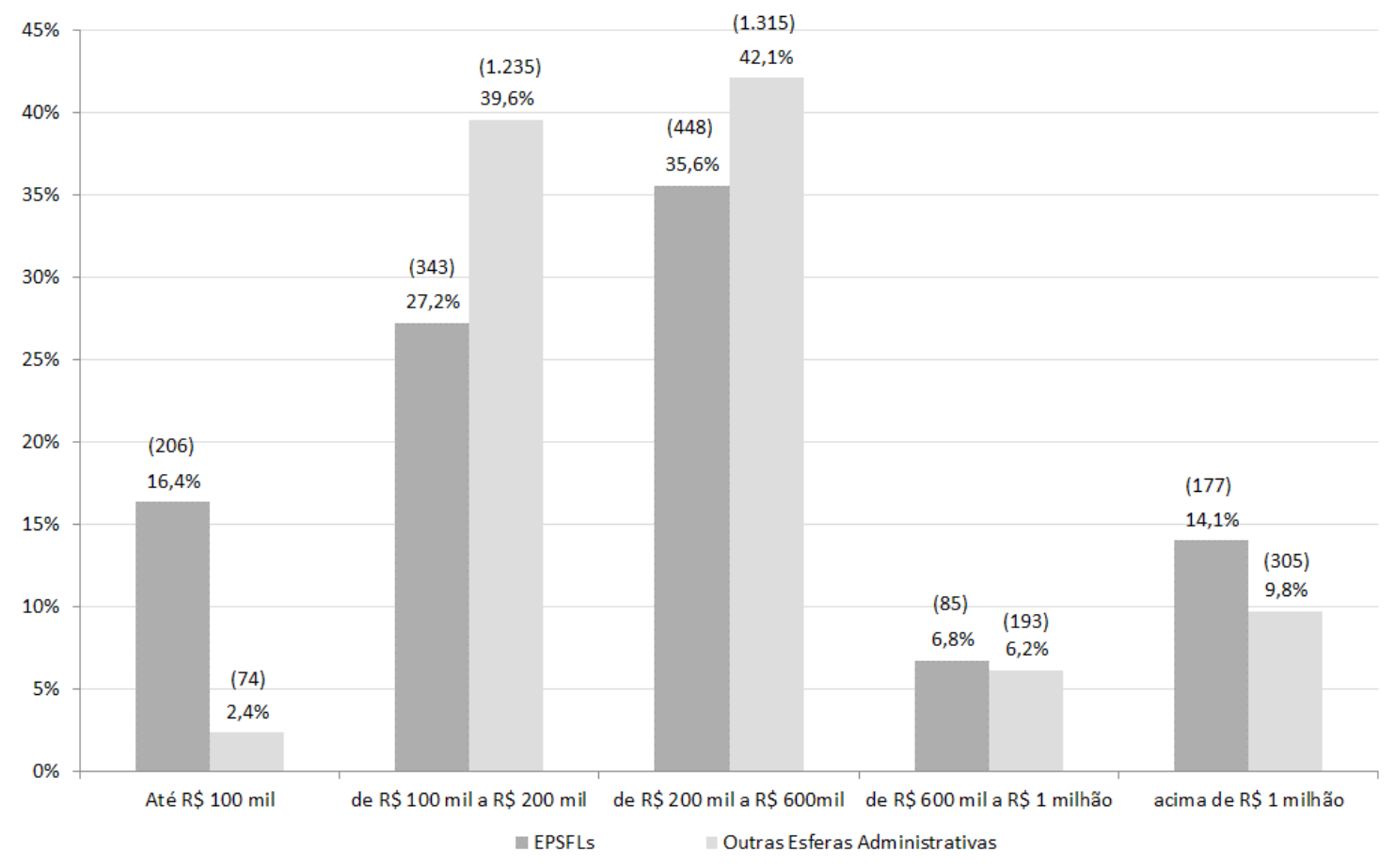

Fonte: SICONV.

Por fim, a Tabela 9 expõe um retrato das parcerias inadimplentes por órgão superior convenente. Observa-se que os órgãos convenentes com maior quantidade de parcerias sem apresentação de prestação de contas são os ministérios do Turismo e da Cultura (357 e 310, respectivamente). Esses números também são relevantes em termos relativos: quase $35 \%$ das parcerias envolvendo o Ministério do Turismo tiveram problemas de inadimplência, enquanto $27 \%$ delas com o Ministério da Cultura tiveram o mesmo problema. Em quantidade de parcerias inadimplentes, observa-se também um número alto de parcerias com o Ministério da Saúde em atraso com a prestação de contas (142), embora com baixa relevância relativa (2,7\% do total). Em termos de participação, despontam com altos porcentuais de inadimplência (apesar da baixa quantidade de parcerias firmadas) os seguintes órgãos: Secretaria dos Portos (40\%), Ministério das Cidades $(29,2 \%)$, Ministério dos Transportes (25\%) e Ministério de Minas e Energia (23,7\%). Em termos de montantes envolvidos, os maiores valores de repasse de parcerias inadimplentes são observados no Ministério do Turismo (R \$ 181 milhões), seguidos pelos seguintes órgãos: Desenvolvimento Agrário ( $R$ \$ 93 milhões), Cultura (R\$ 87 milhões), Saúde (R\$ 85 milhões) e Trabalho e Emprego (R\$ 77 milhões). 
Sergio Goldbaum - Euclides Pedrozo Jr

Tabela 9. Parcerias com EPSFLs finalizadas inadimplentes: órgão superior convenente (2008-2014)

\begin{tabular}{|c|c|c|c|c|c|}
\hline \multirow[b]{2}{*}{$\begin{array}{l}\text { Órgão superior } \\
\text { convenente }\end{array}$} & \multirow[b]{2}{*}{$\begin{array}{l}\text { Total de } \\
\text { parcerias }\end{array}$} & \multicolumn{4}{|c|}{ Parceria inadimplentes } \\
\hline & & Total & $\begin{array}{l}\text { Participação } \\
\text { percentual }\end{array}$ & $\begin{array}{l}\text { Valor de repas- } \\
\text { se das parce- } \\
\text { rias } \\
(\mathrm{R} \$ \mathrm{mil})\end{array}$ & $\begin{array}{r}\text { Valor de repas- } \\
\text { se médio por } \\
\text { parceria (R\$ } \\
\text { mil) }\end{array}$ \\
\hline Ministério do Turismo & 1.023 & 357 & $34,90 \%$ & $180.925,10$ & 506,79 \\
\hline Ministério da Cultura & 1.150 & 310 & $27,00 \%$ & $87.465,06$ & 282,15 \\
\hline Ministério da Saúde & 5.183 & 142 & $2,70 \%$ & $84.790,60$ & 597,12 \\
\hline Ministério do Desenvolvimento Agrário & 623 & 115 & $18,50 \%$ & $93.206,79$ & 810,49 \\
\hline Ministério do Esporte & 526 & 90 & $17,10 \%$ & $72.233,80$ & 802,6 \\
\hline Ministério do Trabalho e Emprego & 363 & 52 & $14,30 \%$ & $77.289,34$ & $1.486,33$ \\
\hline Ministério da Ciência, Tecnologia e Inovação & 241 & 28 & $11,60 \%$ & $52.443,29$ & $1.872,97$ \\
\hline Ministério das Cidades & 89 & 26 & $29,20 \%$ & $21.825,03$ & 839,42 \\
\hline Secretaria de Direitos Humanos & 355 & 24 & $6,80 \%$ & $24.261,52$ & $1.010,90$ \\
\hline Ministério da Educação & 886 & 20 & $2,30 \%$ & $12.200,70$ & 610,04 \\
\hline Ministério da Agricultura, Pecuária e Abastecimento & 384 & 19 & $4,90 \%$ & $3.148,69$ & 165,72 \\
\hline Secretaria Especial de Políticas para as Mulheres & 210 & 16 & $7,60 \%$ & $4.175,94$ & 261 \\
\hline Ministério da Justiça & 230 & 14 & $6,10 \%$ & $9.635,37$ & 688,24 \\
\hline Ministério da Pesca e Aquicultura & 155 & 10 & $6,50 \%$ & $2.788,02$ & 278,8 \\
\hline Ministério de Minas e Energia & 38 & 9 & $23,70 \%$ & $2.405,38$ & 267,26 \\
\hline Secretaria de Políticas de Promoção da Igualdade Racial & 98 & 6 & $6,10 \%$ & 672,71 & 112,12 \\
\hline Ministério do Meio Ambiente & 37 & 6 & $16,20 \%$ & $13.984,06$ & $2.330,68$ \\
\hline Presidência da República - Adm. Direta & 24 & 4 & $16,70 \%$ & $1.738,34$ & 434,58 \\
\hline Ministério do Desenvolvimento Social e Combate a Fome & 41 & 4 & $9,80 \%$ & $2.224,37$ & 556,09 \\
\hline Ministério da Integração Regional & 33 & 3 & $9,10 \%$ & 415,33 & 138,44 \\
\hline Secretaria de Portos & 5 & 2 & $40,00 \%$ & $1.329,20$ & 664,6 \\
\hline Ministério do Desenvolvimento, Indústria e Comércio Exterior & 84 & 1 & $1,20 \%$ & $2.538,50$ & $2.538,50$ \\
\hline Ministério dos Transportes & 4 & 1 & $25,00 \%$ & $13.986,70$ & $13.986,70$ \\
\hline Demais & 59 & 0 & 0 & 0,00 & 0 \\
\hline Total & 11.841 & 1.259 & $10,6 \%$ & $765.683,82$ & 608,17 \\
\hline
\end{tabular}

Fonte: SICONV.

\section{ANÁLISE DOS FATORES QUE INFLUEN- CIAM A PROBABILIDADE DE INADIM- PLÊNCIA}

Nesta seção serão avaliados, com base em um modelo econométrico, se convênios e parcerias firmadas entre a União e as EPSFLs estão mais sujeitas à inadimplência quando comparadas a organismos subnacionais (estados e municípios) e empresas públicas. As informações utilizadas para essa estimativa fazem parte do subconjunto de 38.652 registros de parcerias firmadas com a União e registradas no SICONV, as quais estão finalizadas na data-base de extração dos dados.

Se a hipótese empírica de que a inadimplência é relativamente mais frequente nas EPSFLs for confirmada, reforça-se a hipótese te- 
órica de amadorismo nas EPSFLs, prevista pela Teoria das Três Falhas. Complementarmente, o modelo procura avaliar, também, se a inadimplência está relacionada a outros fatores, como valor da parceria, ano de início ou campo de atuação. Como não é possível observar diretamente o campo de atuação das parcerias no SICONV, optou-se por utilizar o órgão superior convenente como proxy para identificação dessa variável.

O modelo proposto é um probit, no qual a variável dependente de inadimplência (Inadimp) é binária (Inadimp=1 se inadimplente, Inadimp $=0$, caso contrário). A probabilidade de inadimplência em uma parceria ou contrato com a União, portanto, depende do vetor de regressores $X$, de tal sorte que: $\operatorname{Pr}($ Inadim $p=1 \mid \mathbf{X})=\Phi\left(\mathbf{X}^{\top} \beta\right)$

Pr é a probabilidade de inadimplência ( $I n$ $\operatorname{dimp}=1)$, $\Phi$ é a função distribuição cumulativa de uma distribuição normal padronizada, $\mathrm{X}^{\top}$ é a transposta do vetor de regressores. Os parâmetros $\beta$ da regressão são estimados por máxima verossimilhança (Wooldridge, 2006).

Dessa forma, o modelo probit para explicar a probabilidade de inadimplência na prestação de contas dos recursos repassados pela União passa a ser definido por:

$\operatorname{Pr}(\operatorname{Inadim} p=1 \mid X)=\Phi\left(a_{0}+b_{1}\right.$ In Repasse $\left.+b_{2} D_{\text {Ano }}+b_{3} D_{\text {Convenente }}+D_{\text {EPSFL }}+\varepsilon\right)$ em que $\varepsilon$ representa o termo erro aleatório. As variáveis explicativas do modelo são as seguintes:

Repasse: logaritmo natural do valor do repasse do convênio ou parceria.

$D_{\text {Ano }}$ : variável categórica associada ao ano de início do convênio ou parceria, entre 2008 e 2014.

$D_{\text {Convenente }}$ : variável categórica associada aos 29 órgãos superiores convenentes que realizaram parcerias no período de análise, incluindo todos os Ministérios e as secretarias especiais com status de Ministério ligadas à Presidência da República dos Governos de Luiz Inácio Lula da Silva (segundo mandato) e Dilma Rousseff.

$D_{E P S F L}$ : variável dummy associada a entidades privadas sem fins lucrativos (EP$S F L S$ ), sendo $1=E P S F L$ e $0=$ outras entidades (representadas por organismos subnacionais - estados e municípios - e demais empresas públicas).

Foram realizadas duas regressões. A primeira incluiu todos as 38.652 parcerias finalizadas e, a segunda, apenas as 7.373 parcerias finalizadas e realizadas com EPSFLs. Na última avaliação, a variável $D_{E P S F L}$ foi excluída da regressão. Os resultados estão apontados na Tabela 10. 
Tabela 10. Resultado da regressão probit: fatores que influenciam a probabilidade de inadimplência

\begin{tabular}{|c|c|c|c|c|}
\hline & (1) & & $(2)$ & \\
\hline & Inadimplência & & Inadimplência & \\
\hline & $b / p$-value & & $b / p$-value & \\
\hline \multirow[t]{2}{*}{ In(valor do repasse) } & 0,0967 & $* * *$ & 0,0318 & $*$ \\
\hline & $(0,0000)$ & & $(0,0530)$ & \\
\hline \multicolumn{5}{|l|}{ Ano do convênio } \\
\hline \multirow[t]{2}{*}{2009} & 0,0394 & & $-0,0127$ & \\
\hline & $(0,3044)$ & & $(0,8315)$ & \\
\hline \multirow[t]{2}{*}{2010} & 0,1177 & $* * *$ & $-0,0256$ & \\
\hline & $(0,0023)$ & & $(0,6712)$ & \\
\hline \multirow[t]{2}{*}{2011} & $-0,1113$ & & $-0,3395$ & $* * *$ \\
\hline & $(0,0125)$ & & $(0,0002)$ & \\
\hline \multirow[t]{2}{*}{2012} & $-0,2781$ & $* * *$ & $-0,3592$ & $* * *$ \\
\hline & $(0,0000)$ & & $(0,0004)$ & \\
\hline \multirow[t]{2}{*}{2013} & $-0,7633$ & $* * *$ & $-1,0209$ & $* * *$ \\
\hline & $(0,0000)$ & & $(0,0001)$ & \\
\hline \multirow[t]{2}{*}{2014} & $-1,2429$ & $* * *$ & $-1,1724$ & $* *$ \\
\hline & $(0,0035)$ & & $(0,0116)$ & \\
\hline \multicolumn{5}{|l|}{ Órgão convenente } \\
\hline \multirow[t]{2}{*}{ Sec. de Direitos Humanos } & $-0,346$ & & $-0,3553$ & \\
\hline & $(0,2137)$ & & $(0,2768)$ & \\
\hline \multirow[t]{2}{*}{ Sec. Especial de Políticas para as Mulheres } & $-0,4757$ & $*$ & $-0,1787$ & \\
\hline & $(0,0936)$ & & $(0,5975)$ & \\
\hline \multirow[t]{2}{*}{ Sec. de Políticas de Prom. da Igualdade Racial } & $-0,5369$ & & $-0,4264$ & \\
\hline & $(0,1032)$ & & $(0,2525)$ & \\
\hline \multirow[t]{2}{*}{ Sec. de Aviação Civil } & $-0,6194$ & & . & \\
\hline & $(0,2375)$ & & . & \\
\hline \multirow[t]{2}{*}{ Sec. de Portos } & 0,5433 & & 0,7829 & \\
\hline & $(0,2784)$ & & $(0,2225)$ & \\
\hline \multirow[t]{2}{*}{ Sec. da Micro e Pequena Empresa } & . & & . & \\
\hline & . & & . & \\
\hline \multirow[t]{2}{*}{ Min. do Planejamento, Orçamento e Gestão } & . & & . & \\
\hline & $\cdot$ & & $\cdot$ & \\
\hline \multirow[t]{2}{*}{ Min. da Agric., Pecuária e Abast. } & $-0,517$ & $*$ & $-0,547$ & $*$ \\
\hline & $(0,0532)$ & & $(0,0958)$ & \\
\hline \multirow[t]{2}{*}{ Min. da Ciência, Tecnologia e Inovação } & 0,0173 & & $-0,0552$ & \\
\hline & $(0,9496)$ & & $(0,8665)$ & \\
\hline
\end{tabular}




\section{A PRESTAÇÃO DE CONTAS DAS ENTIDADES PRIVADAS SEM FINS LUCRATIVOS EM PARCERIAS COM A UNIÃO (2008 A 2014)}

\begin{tabular}{|c|c|c|c|c|}
\hline \multirow[t]{2}{*}{ Min. da Educação } & $-0,4686$ & $*$ & $-0,4418$ & \\
\hline & $(0,0934)$ & & $(0,1793)$ & \\
\hline \multirow[t]{2}{*}{ Min. do Desenvolv. Ind. e Com. Ext. } & $-0,3773$ & & $-1,1372$ & $* *$ \\
\hline & $(0,2057)$ & & $(0,0261)$ & \\
\hline \multirow[t]{2}{*}{ Min. da Justiça } & $-0,7217$ & $* * *$ & $-0,3791$ & \\
\hline & $(0,0092)$ & & $(0,2635)$ & \\
\hline \multirow[t]{2}{*}{ Min. de Minas e Energia } & 0,2547 & & 0,4425 & \\
\hline & $(0,4417)$ & & $(0,2573)$ & \\
\hline \multirow[t]{2}{*}{ Min. da Saúde } & $-0,1136$ & & $-0,4109$ & \\
\hline & $(0,6704)$ & & $(0,1884)$ & \\
\hline \multirow[t]{2}{*}{ Min. do Trabalho e Emprego } & $-0,0624$ & & 0,0125 & \\
\hline & $(0,8210)$ & & $(0,9690)$ & \\
\hline \multirow[t]{2}{*}{ Min. dos Transportes } & 0,6167 & & 0,3391 & \\
\hline & $(0,1991)$ & & $(0,6591)$ & \\
\hline \multirow[t]{2}{*}{ Min. das Comunicações } & . & & . & \\
\hline & $\cdot$ & & · & \\
\hline \multirow[t]{2}{*}{ Min. da Cultura } & 0,4274 & & 0,4465 & \\
\hline & $(0,1100)$ & & $(0,1514)$ & \\
\hline \multirow[t]{2}{*}{ Min. do Meio Ambiente } & 0,1282 & & 0,4909 & \\
\hline & $(0,6749)$ & & $(0,2542)$ & \\
\hline \multirow[t]{2}{*}{ Min. do Desenvolvimento Agrário } & 0,1209 & & 0,4189 & \\
\hline & $(0,6511)$ & & $(0,1843)$ & \\
\hline \multirow[t]{2}{*}{ Min. do Esporte } & 0,2302 & & 0,108 & \\
\hline & $(0,3887)$ & & $(0,7320)$ & \\
\hline \multirow[t]{2}{*}{ Min. da Defesa } & $-0,2586$ & & . & \\
\hline & $(0,3470)$ & & . & \\
\hline \multirow[t]{2}{*}{ Min. da Integração Regional } & 0,0838 & & $-0,2073$ & \\
\hline & $(0,7553)$ & & $(0,6424)$ & \\
\hline \multirow[t]{2}{*}{ Min. do Turismo } & 0,3108 & & 0,5601 & * \\
\hline & $(0,2430)$ & & $(0,0717)$ & \\
\hline \multirow[t]{2}{*}{ Min. do Desenvolv. Social e Combate a Fome } & 0,2203 & & $-0,0267$ & \\
\hline & $(0,4122)$ & & $(0,9509)$ & \\
\hline \multirow[t]{2}{*}{ Min. das Cidades } & $-0,0008$ & & 1,0872 & $* * *$ \\
\hline & $(0,9975)$ & & $(0,0023)$ & \\
\hline \multirow[t]{2}{*}{ Min. da Pesca e Aquicultura } & $-0,5041$ & $*$ & $-0,5287$ & \\
\hline & $(0,0859)$ & & $(0,1273)$ & \\
\hline Justiça Eleitoral & . & & & \\
\hline
\end{tabular}




\begin{tabular}{|c|c|c|c|c|}
\hline \multirow[t]{2}{*}{ Dummy EPSFL } & 0,3018 & $* * *$ & & \\
\hline & $(0,0000)$ & & & \\
\hline \multirow[t]{2}{*}{ Constante } & $-2,5083$ & $* * *$ & $-1,3243$ & $* * *$ \\
\hline & $(0,0000)$ & & $(0,0004)$ & \\
\hline $\mathrm{N}$ & 38652 & & 7373 & \\
\hline Prob > chi2 & 0,0000 & & 0,0000 & \\
\hline Classificação correta & $88,87 \%$ & & $82,88 \%$ & \\
\hline
\end{tabular}

Fonte: autores.

Os resultados indicam que quanto maiores os valores de repasse, maiores as probabilidades de inadimplência. $O$ coeficiente para os valores de repasse mostrou-se estatisticamente significativo a $1 \%$ na primeira regressão (com a totalidade das parcerias finalizadas) e a $10 \%$ na segunda (com apenas EPSFLs).

Os coeficientes associados aos anos de início das parcerias também se mostraram, em sua maior parte, significativos. No modelo com todas as esferas administrativas, os dois primeiros anos (2009 e 2010) apresentaram sinal positivo e, os demais (2011 a 2014), negativo. Quando se considera a amostra apenas de EPSFLs, todos os coeficientes apresentaram sinal negativo, mas apenas os anos de 2011 a 2014 se mostraram significativos. Esses resultados sugerem que a atenção do governo federal aos convênios e parcerias realizados com EPSFLs aumentou no primeiro governo de Dilma Rousseff em relação ao segundo governo de Lula.

No que concerne aos órgãos superiores convenentes, mostraram-se significativos, na regressão com todas as parcerias, a Secretaria Especial para as Mulheres (10\%), o
Ministério da Agricultura, Pecuária e Abastecimento (MAPA, 10\%), o Ministério da Educação (MEC, 10\%), o Ministério da Justiça (MJ, 1\%) e o Ministério da Pesca e Aquicultura (10\%). Além disso, esses regressores apresentaram sinal negativo, indicando que a probabilidade de inadimplência nesses ministérios é relativamente menor que nos demais órgãos superiores convenentes, considerando-se todas as parcerias e convênios finalizados, quer seja com EPSFLs, quer seja com outros estados e municípios.

Entretanto, o resultado a ser destacado na primeira regressão é que o coeficiente para a variável categórica associada a EPSFLs mostrou-se significativo em $1 \%$ e com sinal positivo, confirmando a hipótese empírica de que se observa maior probabilidade de inadimplência nas EPSFLs do que os demais organismos subnacionais e empresas públicas. $O$ efeito marginal associado às EPSFLs é $5,7 \%$. Em outras palavras, um contrato firmado entre EPSFLs e um órgão convenente tem probabilidade $5,7 \%$ maior de inadimplência em comparação com contratos firmados com outros entes, já controlado pelo valor do repasse, ano de início do contrato e o próprio órgão convenente. 
Tabela 11. Resultado da regressão probit: efeito marginal da variável EPSFL

\begin{tabular}{lcrrr}
\hline \multicolumn{3}{c}{ Delta-method } & & \\
& $\mathrm{dy} / \mathrm{dx}$ & Std. Err. & $\mathrm{z}$ & $\mathrm{P}>|\mathrm{z}|$ \\
\hline 1.d_epsfl & 0,057614 & 0,005219 & 11,04 & 0,000 \\
\hline Note: $d y / d x$ for factor levels is the discrete change from the base level. \\
\hline
\end{tabular}

Fonte: autores

$\mathrm{Na}$ segunda regressão, que incluiu apenas as parcerias e convênios realizados com EPSFLs, os órgãos convenentes, cujos coeficientes se mostraram significativos, foram o Ministério da Agricultura (10\%), o Ministério do Desenvolvimento, Indústria e Comércio $(5 \%)$, ambos com sinal negativo, indicando menor probabilidade do conveniado ser inadimplente. Por outro lado, também se apresentaram significativos os resultados para o Ministério do Turismo (10\%) e para o Ministério das Cidades (1\%), porém com sinal positivo, indicando maior probabilidade de ocorrência de inadimplência nesses ministérios, quando considerados apenas as parcerias e os convênios com EPSFLs.

\section{CONCLUSÃO}

O objetivo deste trabalho foi analisar a prestação de contas nas parcerias firmadas entre a União e as EPSFLs com base nos dados do SICONV, entre 2008 e 2014. Após a introdução, a Seção 2 levantou os elementos teóricos sobre a definição das EPSFLs e o escopo de sua atuação, dando ênfase à questão das falhas voluntárias as quais as organizações sem fins lucrativos podem incorrer.

$\mathrm{Na}$ Seção 3, elaborou-se um retrato da prestação de contas por parte das EPSFLs que firmaram parcerias com a União entre 2008 a 2014 fundamentado nos dados do
SICONV e analisaram-se os resultados. Das características gerais das parcerias entre União e EPSFLs, foi destacado que:

- Das quase 80 mil parcerias celebradas pela União entre 2008 e 2014, a quantidade de parcerias contratadas com entidades da esfera privada representa cerca de $15 \%$ do total.

- Do total de 11.841 parcerias com EPSFLs registradas no SICONV na data-base, 29\% (ou 1.633 parcerias) estavam em execução e, as $71 \%$ restantes, finalizadas.

- A maioria de parcerias, nesse período, foi celebrada junto ao Ministério da Saúde (precisamente: $43,8 \%)$. Seguidos pelo Ministério da Cultura $(9,7 \%)$ e pelo do Turismo $(8,6 \%)$. - Quase $80 \%$ das parcerias celebradas entre a União e EPSFLs estão na faixa de até $\mathrm{R} \$ 600$ mil, em valores nominais (não atualizados).

Em particular, sobre as prestações de contas das parcerias finalizadas da União com EPSFLs, concluiu-se que:

- Para as EPSFLs, $21 \%$ das parcerias finalizadas não entregaram a prestação de contas. Para as outras esferas, o total de parcerias finalizadas que estão nessa situação é inferior (14\%).

- A maior parte das parcerias de EPSFLs inadimplentes foram celebradas em $2009 \mathrm{e}$ 2010. 
- Das 1.389 parcerias com prestação de contas atrasadas por mais de 90 dias, 130 foram caracterizadas com alguma subsituação de ajustes que justificaria o atraso. As outras 1.259 parcerias (ou 16,9\% das parcerias finalizadas) são aquelas que estão inadimplentes e sem nenhuma justificativa de acordo com o SICONV. A proporção de parcerias em atraso com a prestação de contas por mais de 90 dias sem justificativa de ajustes é maior entre as EPSFLs (16,9\% contra apenas $10 \%$ das outras esferas administrativas).

- Do conjunto de parcerias inadimplentes e sem justificativa, a maioria está atrasada a mais de dois anos com a entrega da prestação de contas (998 parcerias ou $79 \%$ ).

- As faixas de valores que mais incidem em inadimplência, independentemente da esfera administrativa, são as que estão entre $R \$$ 100 mil e $\mathrm{R} \$ 600$ mil.

- Os órgãos convenentes com maior quantidade de parcerias sem apresentação de prestação de contas são os ministérios do Turismo (357, ou $35 \%$ das parcerias) e da Cultura (310, 27\%). Em termos de montantes envolvidos, os maiores valores de repasse de parcerias inadimplentes são observados no Ministério do Turismo (R\$ 181 milhões), seguidos pelo Ministério do Desenvolvimento Agrário ( $R$ \$ 93 milhões) e Cultura ( $R$ \$ 87 milhões).

A Seção 4 sugeriu, a partir de um modelo probit, que a inadimplência é mais frequente nas EPSFLs em comparação aos estados, municípios e empresas públicas. $O$ efeito marginal associado à variável é $5,7 \%$. O modelo também sugeriu que a inadimplência diminuiu significativamente nos anos correspondentes ao primeiro governo de Dilma Rousseff quando comparado ao se- gundo governo de Lula. Além disso, entre as parcerias e convênios firmados pela União com EPSFLs, as que apresentaram maior probabilidade de inadimplência foram aquelas firmadas com o Ministério das Cidades e com o Ministério do Turismo. Esses resultados reforçam a hipótese teórica de falhas voluntárias nas entidades privadas sem fins lucrativos e apontam a necessidade de maior atenção nas parcerias e convênios envolvendo áreas de atuação ou órgãos superiores convenentes específicos.

\section{BIBLIOGRAFIA}

Hansmann, H (1980). "The role of nonprofit enterprise". Yale Law Journal, 89:835-901.

Jegers, Marc (2008): Managerial economics of non profit organizations. UK, Routledge (Routledge studies in the management of voluntary and non-profit organizations).

Lopez, F. G., \& Barone, L. S. (2013). As entidades sem fins lucrativos e as políticas públicas federais: tipologia e análise dos convênios e organizações (2003-2011). In: Boletim de Análise Político-Institucional, n. 3, IPEA, Brasília, 2013.

Mendonça, Patricia; Alves, Mario A.; \& Nogueira, Fernando (2013) (orgs.). Arquitetura institucional de apoio às organizações da sociedade civil no Brasil. São Paulo: FGV, p. 25-41.

Powell, W. W., \& Steinberg, R. (2006). The nonprofit sector: a research handbook. 2nd edition. New Haven \& London, Yale U Press.

Salamon, Lester (1987). Partners in public service: The scope and theory of govern- 
ment-non-profit relations. In: E. W. Powell (ed.) The non profit sector: a research handbook. New Heaven: Yale University Press.

Souto, Baiena Feijolo; Pedrozo Jr, Euclides e Goldbaum, Sergio (2015): Perfil das OSCs e de suas Parcerias com a União e Mapa das OSC: Bases de Dados e Resultados Alcançados. Brasília. Consad

Steinberg, Richard. "Economic theories of nonprofit organizations". In: Powell, W. W. and Steinberg, R. (2006): The nonprofit sector: a research handbook. 2nd edition. New Haven \& London, Yale U Press.
TCU - Tribunal de Contas da União: Convênios e outros repasses. 2. ed. Brasília, Secretaria Geral de Controle Externo, 2008.

Weisbrod, B. A. (1975). "Toward a theoy of the voluntary nonprofit sector in a three sector economy. In: Phelps, E. (1975): Altruism, morality and economic theory. NY: Russel Sage.

Wooldridge, J. M. (2006). Introductory Econometrics: A Modern Approach. Mason, $\mathrm{OH}$ : South-Eastern, 5th edition. 